\title{
Surgical palliation in patients with a single ventricle and dextrocardia
}

\author{
Chin L. Poh, BMedSci, ${ }^{\text {a,e }}$ Mary Xu, BMedSci, ${ }^{\mathrm{a}, \mathrm{b}}$ John C. Galati, BSc, PhD, ${ }^{\mathrm{c}, \mathrm{d}}$ Ajay J. Iyengar, MBBS, \\ Michael Cheung, MBBS, ${ }^{f}$ Christian P. Brizard, MD, PhD, ${ }^{\text {be, }}$ Igor E. Konstantinov, MD, PhD, ${ }^{b, e, g}$ and \\ Yves d'Udekem, MD, $\mathrm{PhD}^{\mathrm{b}, \mathrm{e}, \mathrm{g}}$
}

Background: Dextrocardia is found in a significant proportion of patients undergoing a single-ventricle repair. Surgical outcomes in this cohort are unclear.

\begin{abstract}
Methods: The records of 41 consecutive patients with single-ventricle physiology and dextrocardia presenting in a single institution from 1990 to 2008 were reviewed. Of this cohort, 19 patients had heterotaxy syndrome. Twenty-five of the 41 patients had atrioventricular valve regurgitation (AVVR) on presentation (mild, 13; moderate, 9 ; severe, 3 ).

Results: One patient died before intervention. Initial surgical palliation was performed in 31 patients. Four patients died postoperatively and 4 interim deaths occurred between initial palliation and bidirectional cavopulmonary shunt (BCPS). Thirty of the surviving 32 patients underwent BCPS, with 2 perioperative deaths. There were 4 additional deaths before Fontan surgery. Twenty-two of the surviving 25 patients underwent a Fontan procedure. There was 1 postoperative mortality. Survival to the age of 15 years was $56 \%$ (95\% confidence interval $[\mathrm{CI}], 39 \%-70 \%)$. Patients with moderate or severe regurgitation had higher mortality if they were managed conservatively rather than by surgery ( 5 of 6 vs 2 of $6 ; P=.24$ ). Patients with bilateral BCPS had better operative outcomes and survival compared with peers with unilateral anastomosis (odds ratio, 27; $P=.005 ; 95 \% \mathrm{CI}$, 2.7-269). The side of the systemic venous pathway did not seem to influence outcomes.
\end{abstract}

Conclusions: Surgical outcomes of single-ventricle palliation seem poor in patients with dextrocardia. Aggressive management of congenital AVVR might improve the long-term prognosis. (J Thorac Cardiovasc Surg 2014;148:1475-80)

Dextrocardia, defined as cardiac positioning with a rightward base-apex axis, is a rare cardiac anomaly with an estimated incidence of 1 in 10,000 to 12,000 births. ${ }^{1,2}$ Albeit sparse in the general population, a recent review of 212 patients who underwent a univentricular repair in our institution revealed a high incidence of dextrocardia at $11.3 \%{ }^{1}$ The prevalence of univentricular anatomy in patients with dextrocardia has been reported to be $16 \%$ to $25 \% .^{2-4}$ Currently, there are no reports describing the impact of dextrocardia in patients undergoing univentricular repair. After the Fontan procedure, the bulk

From the University of Melbourne ${ }^{\mathrm{a}}$; Murdoch Children's Research Institute ${ }^{\mathrm{b}}$, The Clinical Epidemiology and Biostatistics Unit, ${ }^{c}$ Murdoch Children's Research Institute; Department of Mathematics and Statistics, ${ }^{\mathrm{d}}$ La Trobe University; Department of Cardiac Surgery, ${ }^{\mathrm{e}}$ Department of Cardiology, ${ }^{\mathrm{f}}$ Royal Children's Hospital; Department of Pediatrics, ${ }^{\mathrm{g}}$ University of Melbourne, Melbourne, Victoria, Australia.

This research project was supported by the Victorian Government's Operational Infrastructure Support Program.

Disclosures: Yves d'Udekem is a Career Development Fellow of The National Heart Foundation of Australia (CR 10M 5339). All other authors have nothing to disclose with regard to commercial support.

Received for publication Nov 21, 2012; revisions received Sept 17, 2013; accepted for publication Oct 22, 2013; available ahead of print Feb 16, 2014.

Address for reprints: Yves d'Udekem, MD, PhD, Department of Cardiac Surgery, Royal Children's Hospital, Flemington Rd, Parkville, Melbourne, Victoria 3052, Australia (E-mail: yves.dudekem@rch.org.au).

$0022-5223 / \$ 36.00$

Copyright (c) 2014 by The American Association for Thoracic Surgery

http://dx.doi.org/10.1016/j.jtcvs.2013.10.077 of the ventricular mass on the right side may cause obstruction to the systemic venous pathway draining the inferior vena cava. It is unclear whether a right-sided atrial tunnel or extracardiac conduit should be avoided in this instance.

In addition, there is a known high incidence of heterotaxia in patients with dextrocardia. ${ }^{4}$ The associated variations in both systemic venous and pulmonary drainage pose some operative challenges. The aim of this study was to investigate the outcomes of patients with dextrocardia undergoing single-ventricle palliation with a particular focus on the impact of the side of the routing of the systemic venous pathway.

\section{PATIENTS AND METHODS}

The study protocol was approved by our institutional Human Research Ethics Committee. Between 1990 and 2008, 543 consecutive patients with a functionally single ventricle were admitted to the Royal Children's Hospital, Melbourne, Australia. The records of 41 patients (7.6\%) diagnosed with dextrocardia were reviewed. Their most current follow-up data were gathered from the hospital database and referring cardiologists.

Dextrocardia status, along with all other visceral and vascular parameters were identified from echocardiography, and further verified against intraoperative reports to ensure accuracy. The anatomic details of the patients are described in Tables 1 and 2.

Fifteen of the 41 patients (37\%) had a common atrioventricular (AV) valve. A common $\mathrm{AV}$ valve was present more frequently in patients with heterotaxy ( 13 of $19,68 \%$ vs 2 of $22,9.1 \%$ ). Twenty-five patients had $\mathrm{AV}$ valve regurgitation at diagnosis. AV valve regurgitation (AVVR) was 


$$
\begin{aligned}
& \text { Abbreviations and Acronyms } \\
& \begin{aligned}
\text { AV } & =\text { atrioventricular } \\
\text { AVVR } & =\text { atrioventricular valve regurgitation } \\
\text { BCPS } & =\text { bidirectional cavopulmonary shunt } \\
\text { CI } & =\text { confidence interval } \\
\text { HR } & =\text { hazard ratio }
\end{aligned}
\end{aligned}
$$

more common in patients with heterotaxy ( 16 of $19,84 \%$ vs 9 of $22,41 \%$; $P=.009)$. The morphology of the regurgitant valve of these 25 patients was as follows: common AV valve (12), tricuspid (10), both mitral and tricuspid (2), and mitral (1).

\section{Statistical Analysis}

All continuous data were expressed as the median (interquartile range). Categorical data were expressed as the frequency (percentage). Proportions were evaluated with $\chi^{2}$ analysis. Risk factors for mortality were examined by univariate Cox regression and overall survival of the patient population from birth was illustrated via Kaplan-Meier analysis. The small sample size precluded use of a multivariate analysis to separate the effects of different risk factors on mortality. Logistic regression was used to compare the impact of having a bilateral bidirectional cavopulmonary shunt (BCPS) rather than a unilateral one on mortality and/or postoperative complications after BCPS.

\section{RESULTS}

The list of surgical interventions is shown in Figure 1. One patient with associated cerebral lesions died before surgery took place.

There were 4 in-hospital deaths after the initial neonatal surgery related to myocardial dysfunction. An additional 4 patients died in the interim period between initial palliation and subsequent BCPS procedure. Autopsy was performed in all 4 patients and the following causes of death were identified: aspiration pneumonia (1), respiratory failure (1), unknown (2).

Thirty patients underwent BCPS at a median age of 1.4 years (0.5-5.9 years). Fourteen patients had single BCPS, 10 received bilateral BCPS, and the remaining 6 patients had Kawashima procedures. The cavopulmonary shunts were placed in the left, right, and bilaterally in 7, 9, and 14 patients, respectively.

Two patients died postoperatively. Both patients had difficult postoperative courses with low output syndrome requiring extracorporeal membrane oxygenation. Five patients had the following postoperative complications: arrhythmia (4), thromboembolism (1), heart failure (1), and reoperation for take-down of the BCPS to a BlalockTaussig shunt (1). There were 4 deaths between hospital discharge after BCPS and Fontan surgery or last followup, all sudden unexpected deaths.

\section{Fontan Procedure}

Of the 25 surviving patients, 22 underwent a Fontan procedure at a median age of 5.4 years (1.7-17.2 years). An extracardiac Fontan operation was performed in 17 patients and a lateral tunnel Fontan operation was done in 5 patients. Fourteen of the Fontan conduits were fenestrated. The extracardiac conduits coursed along the left side of the heart in 11 patients and the right side in 6 . Thirteen of the $17 \mathrm{pa}-$ tients who underwent an extracardiac conduit had their conduit on the ipsilateral side of an existing BCPS anastomosis. One patient died after Fontan secondary to low output syndrome. Eleven patients had pleural effusions persisting for more than 2 weeks after surgery. Postoperative recovery course was complicated in 13 patients by arrhythmia (3), bleeding (1), and reoperation for 2 patients for management of postoperative bleeding and mediastinitis.

\section{AVVR}

Twenty-five of the 41 patients $(61 \%)$ had AVVR diagnosed on initial presentation: mild (13), moderate (9), and severe (3). Six of the 12 patients with moderate or severe regurgitation and 2 with mild regurgitation underwent valve repairs. The $\mathrm{AV}$ valve repair was performed shortly after the initial palliation surgery (2), during BCPS (4), after BCPS (1), and during Fontan (1). Two patients required further mechanical valve replacement during the same hospital stay. Later reoperation was necessary in 2 additional patients for further progression of the AVVR.

A total of 10 of the 25 patients with AVVR died. Of the remaining 15 patients, progression in severity from mild to moderate was only noted in 1 patient who was managed conservatively. Amongst the 12 patients with moderate or severe regurgitation, 4 of the 6 who were conservatively managed died and 1 of the 6 who underwent surgery died.

\section{Late Follow-up and Survival Analysis}

There were no further deaths after Fontan completion. Four patients were lost to follow-up. After a median follow-up of 11.2 years (range, 1.2-19.2 years), 20 patients were still alive. Overall survival to 15 years of age was $56 \%$ (95\% confidence interval [CI], 39\%-70\%) (Figure 2). Survivors were in New York Heart Association class I (13), II (4), and III (3). By univariate analysis, transposition of great arteries (hazard ratio [HR], 3.4, $P=.057$; 95\% CI, 0.9711.72 ) and dominant right ventricle (HR, 2.6; $P=.059$; $95 \%$ CI, 0.96-7.08) were associated with poorer postoperative outcomes, but failed to achieve statistical significance (Table 3).

\section{Side of Anastomosis and Outcomes}

Analysis of the relationship between the side of anastomosis and postoperative outcomes failed to reveal a significant relationship for both BCPS and Fontan patients. Two of 9 patients $(22.2 \%)$ with right BCPS anastomoses and 4 out of 7 patients $(57.1 \%)$ with left BCPS anastomosis experienced either a postoperative complication or death. Four of 6 patients $(66.7 \%)$ and 7 of 11 patients $(63.6 \%)$ with 
TABLE 1. Morphologic characteristics of the patient cohort

\begin{tabular}{|c|c|c|c|}
\hline Characteristic & $\begin{array}{l}\text { Total, } \\
\text { n (\%) }\end{array}$ & $\begin{array}{c}\text { With } \\
\text { heterotaxy, } \\
\text { n (\%) }\end{array}$ & $\begin{array}{c}\text { Without } \\
\text { heterotaxy, } \\
\text { n }(\%) \\
\end{array}$ \\
\hline Number of patients & 41 & $19(46.3)$ & $22(53.7)$ \\
\hline \multicolumn{4}{|l|}{ Gender } \\
\hline Male & $24(58.5)$ & $13(68.4)$ & $11(50.0)$ \\
\hline Female & $17(41.5)$ & $6(31.6)$ & $11(50.0)$ \\
\hline \multicolumn{4}{|l|}{ Dominant ventricle } \\
\hline Left & $10(24.4)$ & $2(10.5)$ & $8(36.4)$ \\
\hline Right & $20(48.8)$ & $10(52.6)$ & $10(45.5)$ \\
\hline Biventricular & $8(19.5)$ & $4(21.1)$ & $4(18.2)$ \\
\hline Unknown & $3(7.3)$ & $3(15.8)$ & $0(0)$ \\
\hline Atrioventricular discordance & $7(17.1)$ & $1(5.3)$ & $6(27.3)$ \\
\hline Common atrioventricular valve & $15(36.6)$ & $13(68.4)$ & $2(9.1)$ \\
\hline \multicolumn{4}{|l|}{ Septal defects } \\
\hline Ventricular septal defect & $22(53.7)$ & $6(31.6)$ & $16(72.7)$ \\
\hline $\begin{array}{l}\text { Complete atrioventricular } \\
\text { septal defect }\end{array}$ & $17(41.5)$ & $14(73.7)$ & $3(13.6)$ \\
\hline \multicolumn{4}{|l|}{ Aorta } \\
\hline Right arch & $20(48.8)$ & $9(47.4)$ & $11(50.0)$ \\
\hline Hypoplastic ascending aorta & $4(9.8)$ & $1(5.3)$ & $3(13.6)$ \\
\hline Aortic stenosis & $3(7.3)$ & $0(0)$ & $3(13.6)$ \\
\hline Aortic atresia & $3(7.3)$ & $1(5.26)$ & $2(9.1)$ \\
\hline \multicolumn{4}{|l|}{ Pulmonary veins } \\
\hline $\begin{array}{l}\text { Anomalous pulmonary } \\
\text { venous drainage }\end{array}$ & $9(22.0)$ & $9(47.4)$ & $0(0)$ \\
\hline \multicolumn{4}{|l|}{ Pulmonary valve } \\
\hline Pulmonary stenosis & $22(53.7)$ & $10(52.6)$ & $12(54.5)$ \\
\hline Pulmonary atresia & $11(26.8)$ & $8(42.1)$ & $3(13.6)$ \\
\hline \multicolumn{4}{|l|}{ Superior vena cava } \\
\hline Right-sided & $14(34.1)$ & $3(15.8)$ & $11(50.0)$ \\
\hline Left-sided & $5(12.2)$ & $2(10.5)$ & $3(13.6)$ \\
\hline Bilateral & $22(53.7)$ & $14(73.7)$ & $8(36.4)$ \\
\hline \multicolumn{4}{|l|}{ Inferior vena cava } \\
\hline Right-sided & $30(73.2)$ & $13(68.4)$ & $17(77.3)$ \\
\hline Middle & $3(7.3)$ & $0(0)$ & $3(13.6)$ \\
\hline Left-sided & $8(19.5)$ & $6(31.6)$ & $2(9.1)$ \\
\hline Interrupted & $11(26.8)$ & $9(47.4)$ & $2(9.1)$ \\
\hline \multicolumn{4}{|l|}{ Visceral situs } \\
\hline Solitus & $17(41.5)$ & & \\
\hline Inversus & $5(12.2)$ & & \\
\hline Ambiguous (heterotaxy) & $19(46.3)$ & & \\
\hline \multicolumn{4}{|l|}{ Spleen } \\
\hline Single & $25(61.0)$ & $3(15.8)$ & $22(100)$ \\
\hline Asplenia & $12(29.3)$ & $12(63.2)$ & 0 \\
\hline Polysplenia & $6(14.6)$ & $6(31.6)$ & 0 \\
\hline \multicolumn{4}{|l|}{ Hepatic veins } \\
\hline Right-sided & $29(70.7)$ & $12(63.2)$ & $17(77.3)$ \\
\hline Left-sided & $12(29.3)$ & $7(36.8)$ & $5(22.7)$ \\
\hline Drain into inferior vena cava & $30(73.2)$ & $11(57.9)$ & $19(86.4)$ \\
\hline Drain directly into atrium & $11(26.8)$ & $8(42.1)$ & $3(13.6)$ \\
\hline Intestinal malrotation & $13(31.7)$ & $12(63.2)$ & $1(4.5)$ \\
\hline
\end{tabular}

right and left Fontan anastomoses, respectively, had postoperative complications. One-third of the patients ( 2 of 6 ) with ipsilateral Fontan anastomoses were free of complications,
TABLE 2. Dominant diagnosis of total patient cohort

\begin{tabular}{lc}
\hline \multicolumn{1}{c}{ Diagnoses } & No. of cases $(\mathbf{N}=\mathbf{4 1})$ \\
\hline Double-outlet right ventricle & 13 \\
Tricuspid atresia & 6 \\
Complete atrioventricular septal defect & 6 \\
Hypoplastic left ventricle & 2 \\
Hypoplastic right ventricle & 1 \\
Transposition of great arteries & 3 \\
Pulmonary atresia & 3 \\
Pulmonary stenosis & 2 \\
Aortic atresia & 1 \\
Mitral atresia & 1 \\
Double-outlet left ventricle & 1 \\
Double-inlet right ventricle & 1 \\
Ebstein anomaly & 1 \\
\hline
\end{tabular}

whereas half of the patients with anastomoses between the contralateral inferior vena cava and pulmonary arteries (4 of 8) were complication free.

A review of the effect of the side of BCPS anastomosis on subsequent surgical outcomes was performed. Logistic regression revealed that patients receiving bilateral BCPS anastomosis had less risk of death or complications than those having a unilateral anastomosis (odds ratio $=27$; $P=.005 ; 95 \%$ CI $2.7-269)$.

\section{DISCUSSION}

Dextrocardia, although rare in the general population, is found in a significant proportion of patients with a single ventricle. ${ }^{1}$ Although this anatomic variant has no clinical implications on cardiac function in isolation, it is commonly accompanied by multiple cardiac and extracardiac malformations. ${ }^{1,4}$ Our series is marked by the striking predominance of some morphologic features. Half of our patients had heterotaxia and most of those had a common AV valve. Half had bilateral superior vena cava. Most patients had pulmonary stenosis $(54 \%)$ or atresia $(28 \%)$. At the time of the initial diagnosis, $60 \%$ of the patients had AVVR.

The outcomes of single-ventricle palliation seem to be worse in patients with dextrocardia compared with those with levocardia. Only $56 \%$ of the patients were still alive at the age of 15 years. Our expectation of survival at the age of 15 years for patients offered single-ventricle palliation would be $71 \%{ }^{1}$. The fact that half of the patients had prolonged effusion after Fontan surgery confirms that dextrocardia correlates to the severity of the condition in singleventricle physiology. Dextrocardia has not been singled out in the past as a predictor of an adverse outcome after singleventricle palliation, likely because of the rarity of the condition. It is unclear whether the observed unfavorable outcomes were related to the main or associated cardiac conditions or to the technical difficulties linked to the 


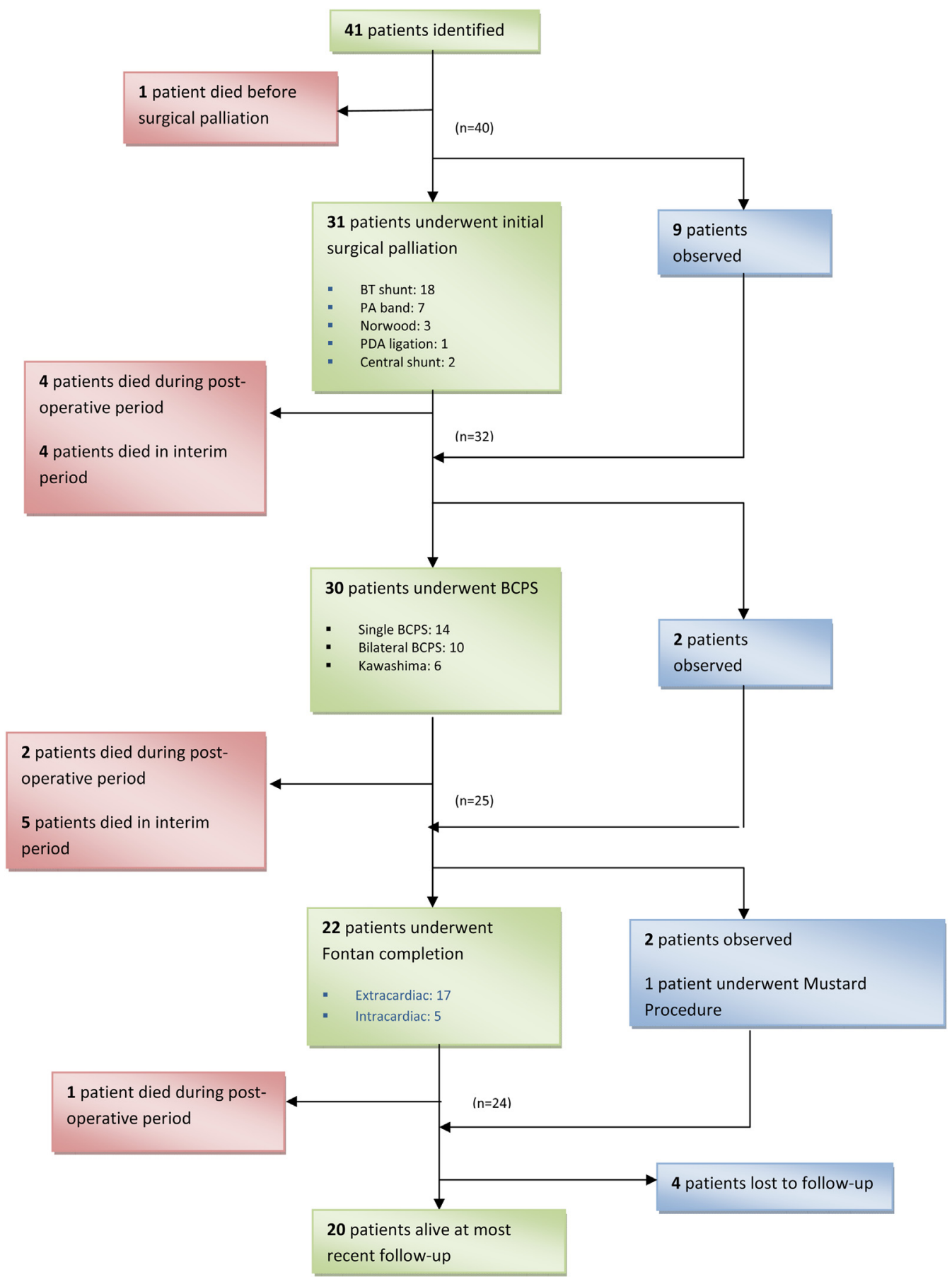

FIGURE 1. Surgical progression of the patient cohort. $B C P S$, Bidirectional cavopulmonary shunt; $B T$, Blalock-Taussig; $P A$, pulmonary artery; $P D A$, patent ductus arteriosus.

position of the heart in the right chest. It has been clearly demonstrated that heterotaxia adversely affects outcomes after single-ventricle palliation. ${ }^{5,6}$ Like others, we have recently shown that patients born with a single ventricle had worse outcomes if they had AVVR..$^{7-9}$ In the current series, the incidence of heterotaxy, common AV valve, and $\mathrm{AV}$ regurgitation at first presentation were $46 \%$,
$36 \%$, and $60 \%$, respectively; in a recent study of our patients with a single ventricle, these incidences were estimated to be $12 \%, 14 \%$, and $13 \%$ only. ${ }^{1}$ There is no doubt that the difficulty of performing AV valve repair is increased by dextrocardia. Notwithstanding these difficulties, it is likely that these patients would benefit from early intervention; considerable mortality occurred in our 


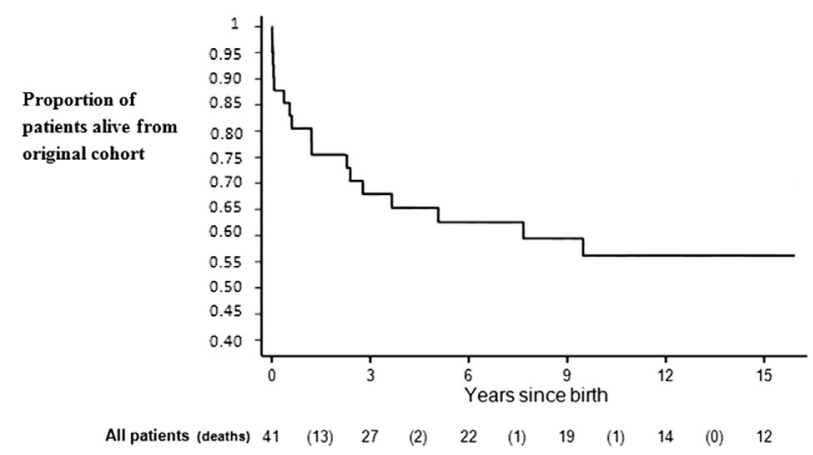

FIGURE 2. Kaplan-Meier survival of the patient cohort.

patients with moderate or severe regurgitation who were managed conservatively.

We tried to determine whether laying the systemic venous pathway on the right side of the chest behind the ventricular mass was associated with adverse outcomes. We similarly investigated the diverse configurations of the Fontan circuit between the inferior vena cava and the pulmonary artery. In this small number of patients, neither the side of the extracardiac conduit nor placing it on the same or the opposite side of the BCPS seemed to influence outcome. Similar findings were demonstrated by Sakurai and colleagues ${ }^{10}$ in their retrospective review of 56 patients with a malpositioned heart and apicocaval juxtaposition. It therefore seems that the surgeon should evaluate the best course of the conduit in each individual patient, and that the passage of an extracardiac conduit behind the ventricular mass should not be precluded. The location of the inferior vena cava or the hepatic veins, the size of the pulmonary vessels, the size of the ventricular and atrial masses, and the requirement to achieve bilateral distribution of the hepatic venous flow, should all influence the decision on the type of Fontan technique used and its side.

In our analysis, the presence of bilateral BCPS was linked to improved outcomes. This finding is in contrast to previous studies showing the detrimental effect of the presence of bilateral vena cava on outcomes after cavopulmonary anastomosis. $^{11}$ The detrimental impact of bilateral BCPS has sometimes been attributed to the risk of developing thrombi between the 2 anastomosis in the area of the pulmonary artery where blood flow is limited. It is possible that, in patients with dextrocardia necessitating complex channeling at the time of the Fontan surgery, having bilateral BCPS confers an advantage in providing a better flow distribution to both lungs.

Because adverse outcomes in these patients with dextrocardia seem to be more related to its association with adverse morphologic features than technical considerations related to the construction of the systemic venous pathway of the Fontan circuit, it is unlikely that these outcomes will improve significantly. Families and practitioners should be aware of these grim outcomes.

This study is limited by its retrospective nature and the rarity of the condition. In addition, patients in this historical review were operated on at a later age than occurs today.

In conclusion, surgical outcomes after single-ventricle palliation seem poor in patients with dextrocardia, likely because of their frequent association with heterotaxy, a common AV valve, and AVVR. Aggressive management of the AVVR might improve the long-term prognosis.

TABLE 3. Cox regression analysis summary of mortality predictive factors

\begin{tabular}{|c|c|c|c|c|c|c|c|}
\hline \multirow[b]{2}{*}{ Factor } & \multicolumn{2}{|c|}{ Present } & \multicolumn{2}{|c|}{ Not present } & \multicolumn{3}{|c|}{ Cox regression } \\
\hline & $\begin{array}{c}\text { Total } \\
\text { no. of patients }\end{array}$ & Died $(\%)$ & $\begin{array}{c}\text { Total } \\
\text { no. of patients }\end{array}$ & Died $(\%)$ & $P$ value & $\begin{array}{c}\text { 95( } \%) \text { confidence } \\
\text { interval }\end{array}$ & $\begin{array}{c}\text { Hazard } \\
\text { ratio }\end{array}$ \\
\hline Transposition of great arteries & 26 & $14(54)$ & 15 & $3(20)$ & .057 & $0.97-11.72$ & 3.36 \\
\hline Dominant right ventricle & 20 & $11(55)$ & 21 & $6(29)$ & .059 & $0.96-7.08$ & 2.61 \\
\hline Situs inversus/ambiguous & 24 & $13(54)$ & 17 & $4(24)$ & .1 & $0.83-7.83$ & 2.55 \\
\hline Heterotaxy syndrome & 19 & $11(58)$ & 22 & $6(27)$ & .12 & $0.81-5.94$ & 2.19 \\
\hline Asplenia/polysplenia & 17 & $10(59)$ & 24 & $7(29)$ & .16 & $0.76-5.28$ & 2.01 \\
\hline Atrioventricular discordance & 7 & $1(14)$ & 34 & $16(47)$ & .18 & $0.03-1.91$ & 0.25 \\
\hline Noncardiac malformation & 18 & $9(50)$ & 21 & $6(29)$ & .26 & $0.64-5.08$ & 1.8 \\
\hline Anomalous hepatic drainage & 11 & $3(27)$ & 30 & $14(47)$ & .26 & $0.14-1.70$ & 0.49 \\
\hline Right hepatic vein & 29 & $13(45)$ & 12 & $4(33)$ & .44 & $0.50-4.78$ & 1.55 \\
\hline Interrupted inferior vena cava & 11 & $6(55)$ & 30 & $11(37)$ & .51 & $0.52-3.79$ & 1.4 \\
\hline Abnormal pulmonary venous drainage & 9 & $5(56)$ & 32 & $12(38)$ & .54 & $0.49-3.94$ & 1.39 \\
\hline Congenital/secondary atrioventricular regurgitation & 35 & $14(40)$ & 6 & $3(50)$ & .55 & $0.20-2.39$ & 0.69 \\
\hline Atrioventricular septal defect & 22 & $9(41)$ & 19 & $8(42)$ & .64 & $0.31-2.06$ & 0.79 \\
\hline Bilateral superior vena cava & 22 & $9(41)$ & 19 & $8(42)$ & .74 & $0.33-2.22$ & 0.85 \\
\hline Congenital atrioventricular regurgitation & 25 & $11(44)$ & 16 & $6(38)$ & .79 & $0.42-3.09$ & 1.14 \\
\hline Common atrioventricular valve & 16 & $7(44)$ & 25 & $10(40)$ & .81 & $0.34-2.33$ & 2.33 \\
\hline Ventricular septal defect & 22 & $7(32)$ & 19 & $10(53)$ & .2 & $0.20-1.39$ & 1.39 \\
\hline Right aortic arch & 20 & $8(40)$ & 21 & $9(43)$ & .9 & $0.36-2.44$ & 0.94 \\
\hline
\end{tabular}




\section{References}

1. d'Udekem Y, Xu MY, Galati JC, Lu S, Iyengar AJ, Konstantinov IE, et al. Predictors of survival after single ventricle palliation: the impact of right ventricular dominance. J Am Coll Cardiol. 2012;59:1178-85.

2. Garg N, Agarwal BL, Modi N, Radhakrishnan S, Sinha N. Dextrocardia: an analysis of cardiac structures in 125 patients. Int J Cardiol. 2003;88:143-55.

3. Bohun CM, Potts JE, Casey BM, Sandor GGS. A population-based study of cardiac malformations and outcomes associated with dextrocardia. Am J Cardiol. 2007;100:305-9.

4. Evans WN, Acherman RJ, Collazos JC, Castillo WJ, Rollins RC, Kip KT, et al. Dextrocardia: practical clinical points and comments on terminology. Pediatr Cardiol. 2009;31:1-6.

5. Bartz P, Driscoll D, Dearani J, Puga FJ, Danielson GK, O'Leary PW, et al. Early and late results of the modified Fontan operation for heterotaxy syndrome: 30 years of experience in 142 patients. J Am Coll Cardiol. 2006;48:2301-5.

6. Kim SJ, Kim WH, Lim HG, Lee CH, Lee JY. Improving results of the Fontan procedure in patients with heterotaxy syndrome. Ann Thorac Surg. 2006;82: $1245-51$.
7. Wong DJ, Iyengar AJ, Wheaton GR, Ramsay JM, Grigg LE, Horton S, et al. Long-term outcomes after atrioventricular valve operations in patients undergoing single-ventricle palliation. Ann Thorac Surg. 2012;94:606-13.

8. Carlo WF, Carberry KE, Heinle JS, Morales DL, McKenzie ED, Fraser CD Jr, et al. Interstage attrition between bidirectional Glenn and Fontan palliation in children with hypoplastic left heart syndrome. J Thorac Cardiovasc Surg. 2011;142:511-6.

9. Honjo O, Atlin CR, Mertens L, Al-Radi OO, Redington AN, Caldarone CA, et al. Atrioventricular valve repair in patients with functional single-ventricle physiology: impact of ventricular and valve function and morphology on survival and reintervention. J Thorac Cardiovasc Surg. 2011;142:326-35.

10. Sakurai T, Kado H, Nakano T, Hinokiyama K, Oda S, Sugiura J, et al. The impact of extracardiac conduit-total cavopulmonary connection on apicocaval juxtaposition. Eur J Cardiothorac Surg. 2010;38:439-44.

11. Tan AM, Iyengar AJ, Donath S, Bullock AM, Wheaton G, Grigg LE, et al. Fontan completion rate and outcomes after bidirectional cavo-pulmonary shunt. Eur J Cardiothorac Surg. 2010;38:59-65. 